\title{
Managing timber and non-timber forest product resources in Canada's forests: Needs for integration and research ${ }^{1}$
}

\author{
by Luc C. Duchesne ${ }^{2}$ and Suzanne Wetzel $^{3}$
}

Non-timber forest products (NTFP) are emerging globally as a tool for the establishment of sustainable forest communities. They provide employment to various sectors of society, draw on local expertise and culture, and increase the outputs of forests. In recent years, NTFP have received accrued interest by the general public, governments and the private sectors of Canada. However, for the NTFP industry to enter mainstream Canadian industrial culture it is now critical to attempt the integration of the timber industry with the NTFP industry to benefit both sectors. NTFP can be harvested from four types of environment: wild stocks from timber-productive forests, wild stocks from non-timber-productive forests or lands, managed stocks from intensively managed forests, and domesticated stocks from agricultural systems. A large body of evidence suggests that NTFP management and harvest can serve the forest industry in many ways. There are four possible types of interaction between the NTFP and timber industries: independent resource use, competition for resources, complementary resource use and symbiotic resource use. Integration of both industries in a sustainable manner will need to be supported with research that address economic, social, policy and ecological questions.

Key words: NTFP, sustainability, biodiversity, community forestry

Les produits forestiers non ligneux (PFNL) émergent sur la scène mondiale comme un outil pour l'établissement des communautés forestières durables. Ils représentent des emplois pour divers secteurs de la société, impliquent l'expertise et la culture locale et accroissent les retombées en provenance des forêts. Au cours des dernières années, les PFNL ont été sujets d'une attention accrue de la part du grand public, des gouvernements et des secteurs privés du Canada. Cependant, pour l'industrie des PFNL puisse faire partie du courant principal de la culture industrielle canadienne, il est essentiel de tenter l'intégration de l'industrie du bois à celle de l'industrie des PFNL pour le bénéfice des deux secteurs. Les PFNL peuvent être récoltés dans quatre types d'environnement: les stocks naturels des forêts de production de bois, les stocks naturels des forêts sans production de bois, les stocks aménagés provenant de forêts sous aménagement intensif et les stocks domestiqués provenant des systèmes agricoles. Il existe plusieurs preuves qui laissent entendre que l'aménagement et la récolte de PFNL peuvent servir les intérêts de l'industrie forestière de plusieurs façons. Il existe quatre types possibles d'interactions entre l'industrie des PFNL et l'industrie du bois : l'utilisation indépendante des ressources, la compétition pour les ressources, l'utilisation complémentaire des ressources et l'utilisation symbiotique des ressources. L'intégration des deux industries d'une manière durable devra être appuyée par des recherches qui répondent aux questions économiques, sociales, politiques et écologiques.

\section{Introduction}

Canada's forests are a collective resource under increasing pressure to support the demands from various national and international entities. In recent years, the forestry profession and the way forestry is conducted across Canada have been the object of unprecedented public debate, which led to the commitment that management should integrate the various resources of the forests. Over the past ten years, Non Timber Forest Products (NTFP) harvesting has grown from a marginal industry to a widespread sector with specific demands and expectations. Indeed, most provincial jurisdictions now address the NTFP industry in one way or the other, either through forestry or agricultural departments. As well, there are several federal departments with vested interests in the NTFP and bioproduct industry.

NTFP-related activities respond to the need for economic and social development (Hardy 2002). The Montreal Process for the identification of criteria and indicators for the conservation and sustainable management of temperate and boreal forests identified NTFP as an important criterion (The Montreal Pro-

${ }^{1}$ Presentation to the Canadian Institute of Forestry, North Bay, Ontario, October 2, 2002.

${ }^{2}$ Natural Resources Canada, Canadian Forestry Service, 1219 Queen St East, Sault Ste. Marie, Ont. P6A 2E5. E-mail: luduches@NRCan.gc.ca ${ }^{3}$ Natural Resources Canada, Canadian Forestry Service, 1219 Queen St East, Sault Ste. Marie, Ont. P6A 2E5. E-mail: Setzel@ NRCan.gc.ca

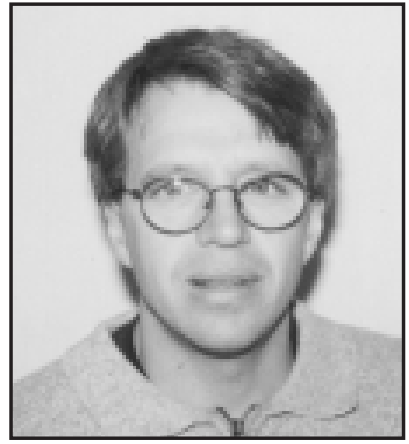

Luc C. Duchesne

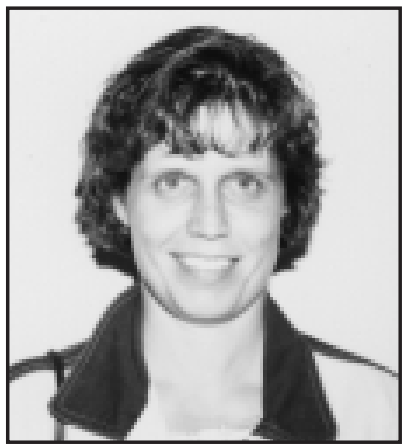

Suzanne Wetzel cess 1997). The NTFP industry is sometimes perceived as conflicting with the timber industry. However, there is a large body of knowledge suggesting that the NTFP industry can be mainstreamed while reducing conflicts. The objective of this paper is to review the different modes of interaction between the timber and NTFP industry.

\section{What Are NTFP?}

NTFP include over 500 types of botanical products (Hadeler 1995, Davidson-Hunt 1998, Hall et al. 1998, Mitchell 1998, Brubacher 1999, Hall and Yun 2000, Duchesne et al. 2001a, 
Marles 2001) derived from the forest and used for food, crafts, clothing, medicinal purposes, and industrial goods. The Food and Agriculture organization also includes wild meats as nonwood forest products (FAO 2002) but all North American researchers exclude wild life products for sustainability reasons. NTFP fall into five general categories, which have been modified from Mohammed (1999).

\section{Food Products}

Food products include wild mushrooms, berries, maple products, nuts, teas, honey, wild rice and other lesser-known wild edibles. Collectively, food products have been at the peripheral of mainstream consciousness as they have been used in our culture for thousands of years by First Nations and since the arrival of settlers in Canada. Today, NTFP food product contribute more than $\$ 200 \mathrm{M} / \mathrm{year}$ to the Canadian economy mainly as maple sap products, mushrooms and berries (Duchesne et al. 2001a). Food products offer many opportunities for value-added products.

\section{Health and Personal Care Products}

This is a broad class that encompasses herbal medicines such as ginseng, medicinal products, fragrances, pet care products, nutraceuticals, pharmaceuticals, and personal care products. Recent data by Health Canada shows that $50 \%$ of Canadians are consumers of nutraceuticals, which are foods that provide more than just nourishment. In 1991, worldwide pharmaceutical sales were roughly $\$ 150$ billions. Considering that roughly 40 percent of drugs sold are derived form plants, then NTFP provide roughly $\$ 60$ billion dollars in drugs annually (Cook and Clapp 2002).

\section{Materials, Manufacturing and Environmental Products}

Because NTFP and waste products from the timber industry occur in large amounts, NTFP have been used for creating various types of industrial commodities. These include essential oils, wood waste products, biofuels (Hall 2002 ), bioplastics and bio-pesticides (e.g., Helson 1992, Ries et al. 2001). Particularly, the use of forest biomass to generate ethanol for fuel is gaining increasing popularity by the forest industry, governments and the general public as it provides renewable and environmentally friendly alternatives to fossil fuel utilization as per the Kyoto Protocol (Hall 2002). As such, this group of NTFP offer great potential for the biotechnology and the timber industries as it will create new commodities from waste products and generate additional revenues from harvesting operations or even create new opportunities for woody species without timber values.

\section{Crafts and Craft Products}

These include specialty value-added products such as wreaths, canoes, smokewood, musical instruments, and ash baskets to name a few. Collectively, these resources feed into already existing markets and draw on long-lasting traditions and culture that have tremendous impact on local economies (De Geus 1995, Emery 1998, Mohammed 1999). For example, balsam fir (Abies balsamea Mill.) branches are manufactured into Christmas wreaths on the south shore of the Gaspé Peninsula of Québec and offer employment for more than 300 workers (unpublished data). With unemployment higher than $20 \%$ (M. Simoneau, personal communication), this industry con- tributes significantly to the local economy. Likewise, there are several similar industries across the country.

\section{Landscape and Garden Products}

These includes trees, shrubs, grasses and other landscaping plants that originate in the forest, along with soil amendments such as waste wood mulches and peat moss. This group includes a number of specialty products with tremendous value to the Canadian economy and include Christmas trees, arts and crafts materials, floral, foliage and branches, as well as carvings and native crafts. The wholesale value of Christmas trees alone is $\$ 90 \mathrm{M} /$ year in Canada $(\mathrm{N}$. Lafrenière, Canadian Tree Growers Association, personal communication).

\section{Socio-economic Value of the NTFP Industry}

The NTFP sector has supported a traditional aboriginal lifestyle for thousands of years; it has also provided supplemental income and seasonal employment for otherwise poor rural communities. In recent years, however, mainstream industries including forestry, agriculture, biotechnology, and pharmaceuticals have started taking advantage of the substantial commercial potential of NTFP (Bioproducts Canada, 2002). It has been estimated that the NTFP industry in Canada alone had the potential to develop into a $\$ 1$ billion industry (Duchesne et al. 2000) without secondary and tertiary transformation, which can yield manifold the economic contribution of non-transformed products (Clay 1992). Experts do not agree about the value of the global NTFP trade as there is no adequate reporting mechanism.

Social sustainability, welfare and cultural survival are measures of the well-being of forests (Moiseev et al. 2002). NTFP offer a rare opportunity to promote social sustainability and development, especially in rural and First Nation communities, by providing various forms of income to a wider section of society than the timber industry's traditional workforce by creating employment for men and women alike, young and old.

\section{Types of NTFP Harvesters}

In order to integrate the forest industry with the NTFP industry it is critical to understand who NTFP harvesters are in Canada. Jones and Lynch (2002) described six types of NTFP harvesters in the United States, which have been modified to meet the unique Canadian reality.

Subsistence harvesters are those people who collect NTFP to satisfy personal food and nourishment needs. Often this type of activity leads to trade and gift-giving through social networks. This is by far the oldest and most widespread form of NTFP harvesting in Canada and draws on long-standing traditions from First Nation and settler communities who have had to rely heavily on NTFP for food, shelter and medicine. Subsistence NTFP harvesting compares to recreational fishing and hunting, which is broadly recognized by forest agencies and is the object of formalized management plans. Whereas sports fishing and hunting are well recognized economic contributorsin Quebec alone they contribute $\$ 3.2 \mathrm{~B} / \mathrm{year}$ - there has been little or no attempt at reporting subsistence NTFP harvesting.

Commercial harvesters collect NTFP with the explicit goal of profit through trading or cash payment and ultimately, employment opportunities or income streams are created through this activity. Commercial harvesting is the most eco- 
nomically significant type of harvesting and the one that needs to be coordinated with the timber industry. At this point in time there is no report of the contribution of commercial NTFP harvesting to the Canadian economy. Commercial harvesters are often self-employed or work on a per-pound basis and as such, their revenues often fall into the so-called black market, which is viewed as a loss of fiscal revenues to governments. Employment may be seasonal and is often associated with opportunities such as presence of unique resources as well as processing facilities in the proximity of workforce. There is a broad range of selling mechanisms ranging from informal retailing on roadsides, formal retailing in shops as well as wholesaling. Emery (1998) described the NTFP industry of Michigan as "invisible livelihoods," which applies to Canada's commercial harvesters as well.

Recreational harvesters collect NTFP for pleasure or exercise and do not emphasize the need for supporting a family. Typically, they collect small amount of resources and their need creates little or no ecological pressure on the species they collect. However, provision must be made to allow such harvesters to collect NTFP at will in respect to long-established traditions.

Spiritual harvesters view NTFP from a spiritual perspective. This type of harvester is represented by all age groups, gender and ethnicities even if it may also be subsistence, recreational or commercial in nature (Jones and Lynch 2002). This activity takes several forms. For example the Anishenabe around the Sault Ste. Marie, Ontario area collect sweet grass (Hierochloe odorata L.) for spiritual reasons and there is a prohibition to profit from its harvest.

Healing harvesters are those who gather NTFP for the purpose of healing themselves, other people, animals or other entities. There is a long tradition of NTFP harvesting by healing harvesters in Canada, which is continued by various ethnic groups. This knowledge is the object of bioprospection (e.g., Marles 2001) and has a great deal of potential for economic development in First Nation and rural communities.

Scientific harvesters harvest NTFP for scientific purposes for cataloguing, domesticating, demonstration harvesting or bioprospecting (Duchesne et al. 2001b). With accrued interest in this field there should be increased scientific harvest. Bioprospecting is conducted by pharmaceutical and nutraceutical companies in search of new drugs, herbs or applications. One recent example of bioprospection is the finding that paclitaxel is found in the needles of Canadian yew (Taxus canadensis L.) (Zhang et al. 2000). Viewed from this perspective the NTFP industry provides an economic value to biodiversity (Peters et al. 1989).

\section{Sources of Raw Material for the NTFP Industry}

To date, there has been little attempt at integrating the nontimber forest product and timber industries, which reflects the fact this has never been mainstreamed in the Canadian culture. However, globalization of markets, increase in the demand for NTFP and their value-added products, and the need to create sustainable forest communities suggest that it would be in every- one's best interest to coordinate both types of industries. For this, we need to understand the origin of raw material for the NTFP industry. In practice, NTFP harvesting — and this applies to all NTFP types - can be made from the following.

\section{Wild Stocks from Timber-productive Forests}

In nature, each NTFP has its own set of ecological requirements. There is a great deal of information showing how the abundance of NTFP varies with their unique ecological requirements and phenology. Some are specialists for early successional ecosystems, some are unique to late successional ecosystems and some are ubiquitous. For example, in the boreal forest of northwestern Ontario the commercial mushroom Morchella spp is found only in one-year-old post-burn communities (Duchesne and Weber 1993), chanterelles (Cantharellus spp) are found in mid successional stands, and pine mushrooms (Tricholoma magnevelare (Peck) Redhead) are found uniquely in old (>60 year-old) forest stands (A. Chapeskie, personal communication).

Because NTFP and timber are harvested from the same lands, there is potential for conflicts. It is important to emphasize that some species such as blueberries (Vaccinium spp) in eastern Canada and salal (Gautheria shallon Pursh) in western Canada are NTFP that are favoured by logging disturbance. However, this type of harvest, if broadened, may come at an ecological cost especially if wild stocks are already depleted (Nantel et al. 1996, Lamoureux and Nantel 1999). For example, the commercial exploitation of American ginseng (Panax quinquefolius L.) started in 1720 in the United States (Foster 1995), and led to the depletion of wild stocks (Nantel et al. 1996).

\section{Wild Stocks from Non-timber-productive Forests or Lands}

The density, abundance and types of wild stocks from non-timber-productive forests are similar to NTFP from timber-productive forests. However, their origin excludes the possibility of direct competition for resources with the timber industry. These include forests that are not suitable to timber harvesting for reason of growth rate, topography, species composition, topography, legislation, or land uses that are not compatible with timber management. Drainville (1996) harvested white spruce resin from bark wounds on trees located in protective bands along streams and lakes. Transmission line corridors are also a good source of NTFP and can be the object of NTFP management to meet the double goal of eliminating the need to control vegetation and increase yields from the land (Saari 1993). Likewise, NTFP management on private lands offers income opportunities to landowners who are not willing or able or both to manage timber resources (Ihalainen et al. 2002).

\section{Managed Stocks from Intensively Managed Forests}

Managed stocks from intensively managed forests offer many opportunities to increase the social and economic value of forests by increasing the number of commodities extracted. Recently, le Ministère des Ressources Naturelles du Québec took a landmark initiative by promoting the intensive management of blueberries along with timber values in alternating strips of timber and blueberries (Anonymous 2002). It was demonstrated that the outputs of suitable ecosystems is increased by intensively managing fibre (yields increases from 
$1.8 \mathrm{~m}^{3} / \mathrm{ha} /$ year to $4.7 \mathrm{~m}^{3} / \mathrm{ha} /$ year), which frees up roughly $60 \%$ of the land for the intensive production of blueberries (Anonymous 2002). This initiative was prompted by local blueberry harvesters, who are faced with demands that exceed the availability of current stocks.

Similarly to blueberries, there are many instances where the demands for NTFP dictate that NTFP should be managed intensively in similar ago-forestry systems. Often commercial harvesters are forced to extract raw material over large tracts, which decreases their profits. There are many medicinal plants, and berry-producing species (Mohammed 1999) that can be co-managed with timber values without conflict between the two types of industries.

\section{Domesticated Stocks in Agricultural Systems}

Cultivation of NTFP species in agricultural settings is sometimes used as a means to eliminate the problems associated with finding scant resources from the wild (e.g., Ripa 1993). As well, it creates a system that regularizes supplies of raw materials. Early attempts at growing Taxus brevifolia Nutted. in nurseries for the production of taxol is an excellent example of this problem (Wheeler and Hehnen 1992). As well, in the case of the Christmas tree market, consumers demand products that are unique in shape and quality that could not be extracted from the wild. Across Canada there are several initiatives to domesticate many native plants (e.g., Montgomery 2000) and this concept is appealing to the agricultural industry as it offers novel, often more lucrative, crops. However, domestication in agricultural settings may come at a cost for the American ginseng as field-grown roots have a lower ginseoside content than forest-grown roots (Ma et al. 1995).

\section{Modes of Interaction Between the NTFP and Timber Industries}

The interaction between the NTFP and timber industries varies according to where they extract their raw material and how it affects the other industry. Hence, all interactions between these industries fall under the following four types: competition, complementary resource use, symbiotic resource use and independent resource use. Interestingly, these modes of interaction vary with the intensity of integration between the timber and NTFP industries.

\section{Independent Resource Use}

In this least integrated system of integration the two industries use different lands as sources of raw material and there is little or no overlap between them. Typically the needs of harvesters are met by exploiting the resources from non-timber-productive forests, private wood lots, or infrastructure corridors, to name a few. As such, there is no formal relationship between the timber and NTFP industries. However, as the demand for NTFP increases, or the NTFP resources from non-industrial forests decline, or both, NTFP harvesters turn to industrial forests as a source of raw material.

\section{Competitive Resource Use}

In this type of interaction, competition or the impression of competition takes place as there is no attempt at integrating timber and NTFP management. In the worst case scenario, both industries lay claim to the same piece of land for resource extraction and management strategies are in conflict (Belonogova 1993).
For example, widespread maple tapping in commercial hardwood stands would be devastating to the logging industry as it would reduce wood quality. Likewise, clearcut logging in oldgrowth forests stands would be devastating to the pine mushroom industry in western Canada. To take this example to the extreme, it would be irresponsible to burn large tracts of forests in order to stimulate the production of black morels, which are fire-dependant species (Duchesne and Weber 1993). Conflicts arise from a lack of communication and planning between the timber and NTFP industries and can be resolved by proper multi-resource planning, which should lead to complementary or even symbiotic resource use.

\section{Complementary Resource Use}

In this type of interaction the two industries extract raw material from the same territories in non-conflicting ways, which denotes an increased level of coordination. With the example of the black morels, coordination between the two industries can be achieved by providing morel harvesters with the locations of recent burns. Coordination can also address the use of logging residues, use of unwanted species or use of early successional habitats. On the one hand, craftspeople using birchbark (Betula papyrifera Marsh), black ash (Fraxinus nigra Marsh), Lycopodium spp, balsam fir (Abies balsamea Mill.) boughs benefit a great deal from the timber industry, which creates access roads to these resources. In practice, little coordination is needed to meet the needs of craftspeople while increasing the yield from forests. On the other hand, many fruit-bearing species, with blueberries as a well-known example, are more abundant in early successional ecosystems and benefit from forest operations. Berry harvesting is a unique situation, as the NTFP industry benefits from logging disturbance long after cutting operations.

\section{Symbiotic Resource Use}

This types of interaction takes place when both industries benefit equally from coordinated operations. Benefits may be derived from co-management of resources and involves generation of revenues that increase land economic productivity and satisfies the needs of both industries (Higgins 1998). Agroforestry systems are emerging as one type of symbiotic resource use (e.g., Beyfuss 1999). As well, active management of wild stocks as well as modification of the logging regime to maintain ecosystem characteristics are also possible (Amaranthus et al. 1998, Anonymous 2002). In the ultimate system of symbiotic use, NTFP revenues would be used to support silvicultural operations (Anonymous 2002) and silvicultural operations are conducted in ways that maintain or increase NTFP values.

\section{Research Needs and Future Direction}

Worldwide, the NTFP industry has a demonstrated record of providing sustainable livelihood from forests. In Canada, NTFP resources and markets are largely untapped, mostly because of the perception that this industry is marginal, supports underground economies, and may compete with the timber industry. Managing forests to meet the demands of both the timber and the NTFP industries may be a way to offset the losses of jobs from the timber industries generated by international disputes over softwood lumber tariffs while revitalizing forest and First Nation communities. Although there is growing recognition of the socio-economic potential of the NTFP 
industry, there is a need for research in a way that is comparable to the research efforts that were initiated to support the growing timber industry at the beginning of the $20^{\text {th }}$ century (Johnstone 1991).

From an economic standpoint we need to determine the benefits of including NTFP and value-added wood products in industrial forestry. How can the benefits per acre of a forest be maximized? How can the NTFP industry be integrated with current timber-based industries? This will focus on maximizing returns from forests by considering the revenues generated from timber values as well as NTFP from various stand ages (e.g., early post-disturbance, canopy closure and mature). Benefits could also be maximized by utilizing waste products, such as slash and wood residues. Existing data can be utilized to demonstrate the benefits on integrating NTFP into forest management.

Social research should determine how the inclusion of NTFP into forest management will improve the social welfare of communities. There is a need to derive social indicators that will demonstrate how NTFP increase the social welfare of a forest-dependent community. There are many benefits from including NTFP in forest management that relate to people's enjoyment of the forest more than individual economic benefit. How does a community-based tenure system ensure that people's enjoyment of the forest is included in forest management? There may need to be indicators that can be utilized by community-based tenure forest management systems, which are different than those of classical industrial forestry.

Policy issues need to address the opportunities and constraints of integrating NTFP into forest management, especially for Aboriginal communities. What is the existing policy, legal and regulatory framework of NTFP harvesting within the timber industry? There is also a need to address the policy, legal and regulatory framework of NTFP processing and marketing. What are the opportunities and constraints of existing processing and marketing regulations for NTFP? Finally, how does the policy, legal and regulatory framework ensure that holders of local knowledge benefit from inclusion of NTFP into forest management? How does the policy, legal and regulatory framework allow people to reconcile traditional and commercial values?

Biological research needs to determine what NTFP are available in different categories and ages of forest. What is the sustainable harvest level from different forest categories? What management interventions could increase the yield of different forest categories? There is much data that can be analyzed to provide initial answers to these questions and assist in the creation of effective symbiotic resource uses across Canada's commercial forests.

The upcoming years should prove to be an exciting time as the NTFP industry develops into a vibrant component of the forest industry and contributes to the creation of sustainable forest communities.

\section{References}

Amaranthus, M.P., J. Weigand and R. Abbott. 1998. Managing high-elevation forests to produce American matsutake (Tricholoma magnevelare), high quality timber, and nontimber forest products. Western Journal of Applied Forestry 13:120-128.

Anonymous. 2002. Rapport du comité interministériel sur la contribution des terres du domaine de l'état au développement de l'industrie du bleuet. Ministère des Ressources Naturelles, Direction à la planification et des communications, Charlesbourg, Québec. 60 p.
Belonogova, T. 1993. Changes in bilberry and cowberry yields under the influence of forestry measures. Aquilo Ser. Bot. 31:17-20. Beyfuss, R.L. 1999. American ginseng production in woodlots. Agroforestry Notes No. 14. USDA National Agroforestry Center. Lincoln, Nebraska. 4 p.

Bioproducts Canada. 2002. www.bioproducts.com (October 2002). Brubacher, D. 1999. Non timber forest products: exploring opportunities for Aboriginal communities. National Aboriginal Forestry Association, Ottawa, ON. 135 p.

Clay, J. 1992. Some general principles and strategies for developing markets in North America and Europe for non timber forest products: lessons from cultural survival enterprises, 1989-1990. Advances in Economic Botany 9:101-106.

Cook, C. and R. A. Clapp. 2002. The paradox of market-oriented conservation: lessons from the tropical forests. In E.T. Jones, R.J. McLain and J. Weigand. Non timber forest products in the United States. pp. 163-179. University of Kansas Press.

Davidson-Hunt, I. 1998. Non timber forest products-definitions and meanings. Boreal Culturescapes Newsletter. 1: 2-3. Taiga Institute, Kenora, ON.

De Geus, P.M.J. 1995. Botanical forest products in British Columbia: an overview. Victoria, BC: Integrated Resource Policy Branch, British Columbia Ministry of Forests. 51 p.

Drainville, L. 1996. Evaluation du potential d'exploitation des resources forestières non traditionnelles: pièces de bois aux formes utilitaires et décoratives. Spores de Lycopodes, feuilles de thé et gomme d'épinette. Essais, expérimentation et transfer technologique en foresterie. Projet No 1109. Service d'extension en foresterie de l'est du Québec, Causapuscal, Québec. 23 p.

Duchesne, L.C. and M.G. Weber. 1993. High incidence of Morchella conica ascocarps in a pine forest following prescribed fire. Can. Field Nat. 107: 114-116.

Duchesne, L.C., J. Zasada and I. Davidson-Hunt. 2000. Nontimber forest product industry in Canada: Scope and research needs. For. Chron. 76: 743-746.

Duchesne, L.C., J. Zasada, and I. Davidson-Hunt. 2001a. Ecological and biological considerations for sustainable management of non-timber forest products in northern forests. Forest Communities in the Third Millennium. In Proceedings, Linking Research, Business, and Policy Toward a Sustainable Non-Timber Forest Product Sector, Kenora, Ontario, Canada. pp. 102-109. Gen. Tech. Rep. NC-217. USDA, Forest Service, North Central Research Station, St. Paul, MN.

Duchesne, L.C., J. Zasada and I. Davidson-Hunt. 2001b. The future of the NTFP industry. Forest Communities in the Third Millennium In Proceedings, Linking Research, Business, and Policy Toward a Sustainable Non-Timber Forest Product Sector, Kenora, Ontario, Canada. pp. 149-151. Gen. Tech. Rep. NC-217. USDA, Forest Service, North Central Research Station, St. Paul, MN.

Emery, M. 1998. Invisible livelihoods: non timber forest products in Michigan's Upper Peninsula. PhD Dissertation. Rutgers University. $232 \mathrm{p}$.

FAO. 2002. www.fao.org (October 2002).

Foster, S. 1995. Forest Pharmacy: Medicinal plants in American forests. Durham, NC: Forest History Society. 194 p.

Hadeler, H. 1995. Medicinal mushrooms you can grow for health, pleasure and profit. The Cariaga Publishing House, Sechelt, BC. 194 p. Hall, I.R. and W. Yun. 2000. Edible mushrooms as secondary crops in forests. Quarterly Journal of Forestry 94: 299-304.

Hall, I.R., P. Buchanan, Y. Wang. and A.L.J. Cole. 1998. Edible and poisonous mushrooms: an introduction. New Zealand Institute for Crop and Food Research, Christchurch, New Zealand.

Hall, J.P. 2002. Sustainable production of forest biomass for energy. For. Chron. 78: 391-396.

Hardy, Y. 2002. The Canadian Forest Service: New directions for science and technology. For. Chron. 78: 57-59.

Helson, B.V. 1992. Naturally-derived insecticides: prospects for forestry use. For. Chron. 68: 349-354. 
Higgins, C. 1998. Innovative forestry practice agreements - What could be done that would be innovative? For. Chron. 75: 939-942. Ihalainen, M., J. Alho, O. Kolehmainen and T. Pukkala. 2002. Expert models for bilberry and cowberry yields in Finnish forests. Forest Ecology and Management 157: 15-22.

Johnstone, K. 1991. Timber and trauma: 75 years with the federal forestry service 1899-1974. Forestry Canada. Ottawa Ontario. 194 p.

Jones, E.T. and K. Lynch. 2002. The relevance of socio-cultural variables to non-timber forest product research, policy and management. In E.T. Jones, R.J. McLain, and J. Weigand (eds.). Non timber forest products in the United States. pp. 26-51. Kansas University Press.

Lamoureux, G. et P. Nantel. 1999. Cultiver les fleurs sauvages sans leur nuire. Fleubec, Levis, Que. 80 p.

Ma, Y.C., J Zhu, L. Benkrima, M. Luo, L.H. Sun, S. Sain, K. Kont and Y.Y Plaut-Carcasson. 1995. A comparative evaluation of ginseosides in commercial ginseng products and tissue culture samples using HPLC. Journal of Herbs, Spices and Medicinal plants 3: 41-50.

Marles, R. 2001. Non-timber forest products and Aboriginal traditional knowledge. Forest Communities in the Third Millennium. In Proceedings, Linking Research, Business, and Policy Toward a Sustainable Non-Timber Forest Product Sector, Kenora, Ontario, Canada. pp. 53-65. Gen. Tech. Rep. NC-217. USDA, Forest Service, North Central Research Station, St. Paul, MN.

Mitchell, D.A. 1998. Non-timber forest products in British Columbia: The past meets the future on the forest floor. For. Chron. 47: 359-362.
Mohammed, G. 1999. Non-timber forest products in Ontario: an overview. For. Res. Inf. Pap. 145. Ontario Forest Research Institute, Sault Ste. Marie, ON. 64 p.

Moiseev, A., E. Dudley and D. Cantin. 2002. The well-being of forests: an e-tool for assessing environmental and social sustainability. IUCN, Gland, Switzerland and Cambridge, UK. 50 p.

Montgomery, T. 2000. Using native plants to link local agriculture initiatives with environmental stewardship. http://www.cityfarmer.org/nativecrops.html (October 2002).

Nantel, P., D. Gagnon and A. Nault. 1996. Population viability analysis of American ginseng and wild leek harvested in stochastic environments. Conservation Biology 10: 608-621.

Peters, C.M., Gentry, A. and R. Mendelsohn. 1989. Valuation of an Amazonian rainforest. Nature. 339: 655-656.

Ries, S., R. Buaghan, M.G. Nair and R. Schutzki.. 2001. Repelling animals from crops using plant extracts. Hortechnology 11: 302-307. Ripa, A.K. 1993. Introduction of the cowberry (Vaccinium vitis-idaea) into cultivation. Aquilo. Ser. Bot. 31: 55-58.

Saari, V. 1993. Collection of products of transmission-line corridors and their utilization possibilities. Aquilo. Ser. Bot. 31: 47-54.

The Montreal Process. 1997. Working group on criteria and indicators for the conservation and sustainable management of temperate and boreal forests. First Approximation report. The Montreal Process Liaison Office, Ottawa. 47 p.

Wheeler, N.C. and M.T. Hehnen. 1992. Taxol. Journal of Forestry 41: 15-18.

Zhang, J., F. Sauriol, O. Mamer and L.O. Zamir. 2000. Taxoids from the needles of the Canadian yew. Phytochemistry 54: 221-230. 